\title{
AN UNCOMMON COMPLICATION POST TRANSPHENOIDAL SURGERY FOR PITUITARY ADENOMA
}

\author{
Hiang Leng Tan, Kurien John
}

Diabetes and Endocrinology Department, Weston General Hospital, Weston Super Mare. United Kingdom

\section{INTRODUCTION}

The commonest complications post trans-sphenoidal surgery is diabetes insipidus and the development of anterior pituitary hormone deficiencies. Other complications include meningitis, CSF leak, visual deterioration, haemorrhages and transient hyponatremia.

$\square$ We present a case of pituitary abscess 6 months post pituitary surgery who presented with viral meningitis and pan hypopituitarism.

\section{CASE REPORT}

A 55 year old lady presented with a 3 weeks history of tiredness, headache, visual disturbances and pyrexia. She had an uncomplicated trans-sphenoidal adenomectomy surgery (TSA) for Thyroid stimulating hormone (TSH) and Growth hormone $(\mathrm{GH})$ secreting adenoma 6 months previously.

- She had evidence of pan hypopituitarism with a peak cortisol response of a short synacthen test of $280 \mathrm{nmol} / \mathrm{L}$ at 30 minutes, adrenocorticotropic hormone level of $<5 \mathrm{ng} / \mathrm{L}$, low gonadotrophin, low free T3 and inappropriately normal thyroid-stimulating hormone. A lumbar puncture was done showing evidence of viral meningitis.

- Initial Magnetic Resonance Imaging (MRI) of pituitary (Figure 1) showed evidence of likely recurrence of her pituitary adenoma. However, due to the presence of pyrexia and viral meningitis a MRI pituitary with contrast (Figure 2) was subsequently performed. This confirmed evidence of multiloculated pituitary abscess with optic chiasm compression. She was commenced on intravenous hydrocortisone, thyroxine, intravenous acyclovir and antibiotics and transferred to a neurosurgical centre for drainage of the abscess.

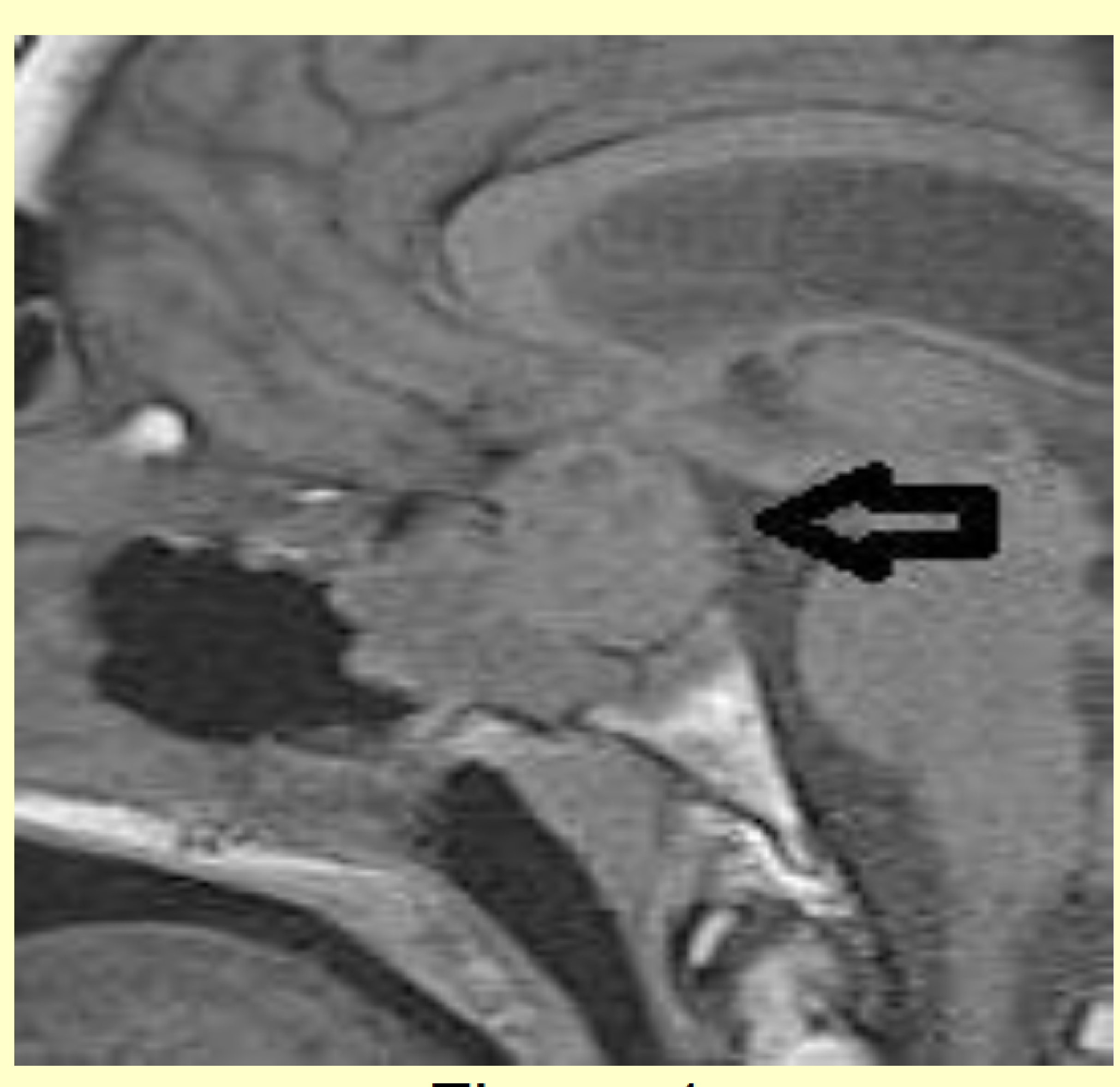

Figure 1

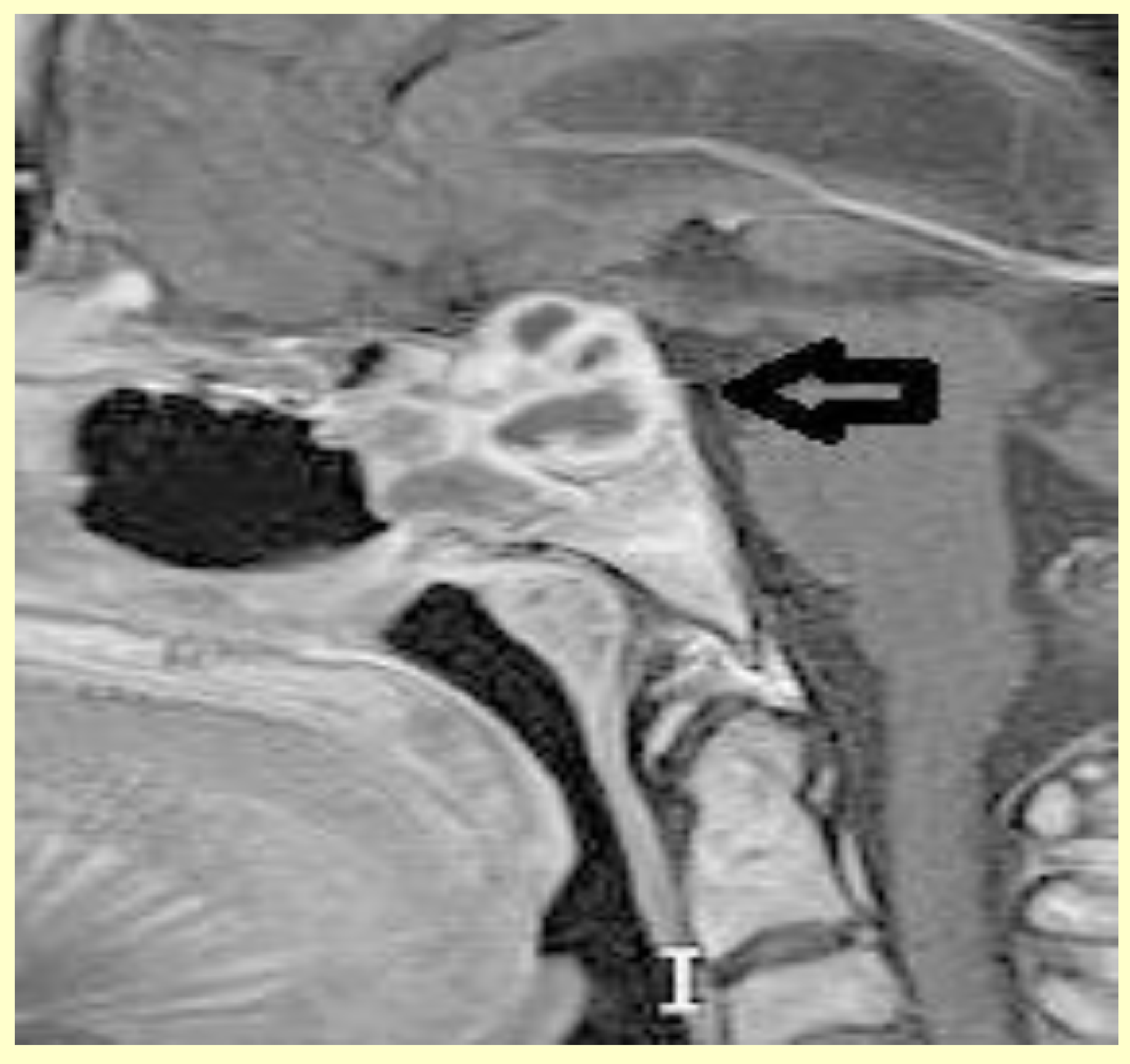

Figure 2

\section{CONCLUSIONS}

Pituitary abscess is a rare complication post transphenoidal surgery. Mortality is high and high index of suspicion is important as early surgical drainage is required for definitive treatment.

$\square$ In a patient with hypopituitarism and a sellar mass, pituitary abscess should be borne in mind if there are systemic signs of infection especially in a patient post pituitary surgery.

$\square$ When suspecting this condition, a MRI with contrast enhancement must be performed to look for evidence of ring enhancing lesion typical of abscess. 